\title{
THE CONTROL OF RENAL BLOOD FLOW AND GLOMERULAR FILTRATION IN NORMAL MAN
}

\author{
BY HERBERT CHASIS, HILMERT A. RANGES, WILLIAM GOLDRING AND \\ HOMER W. SMITH \\ (From the Departments of Physiology and Medicine, New York University College of \\ Medicine, and the Third (New York University) Medical Division \\ of Bellevue Hospital, New York City)
}

(Received for publication June 7, 1938)

This report is concerned with the effective renal blood flow and rate of glomerular filtration in normal man, as determined by the diodrast and inulin clearances (26) during diuresis and during the action of phlorizin, adrenin, caffeine, nitrite, and typhoid vaccine. The observations not only throw light on the action of these agents, but also afford information concerning the physiological control of renal blood flow and glomerular activity.

Typical data are reported graphically. On the assumption that the diodrast plasma clearance (indicated by $\mathrm{D}$ in the figures) is a complete clearance, this value is taken as equal to the effective renal plasma flow, i.e., the flow of plasma to active excretory tissue. To convert this figure to the effective whole blood flow it is only necessary to divide it by the per cent of plasma in the blood. For brevity, the term "effective" will be omitted from the discussion without, however, neglecting the physiological distinction between the diodrast clearance and the actual plasma flow which must be somewhat larger than the former in consequence of the inclusion of inert tissue. The filtration rate has been measured by the inulin cleararce (IN). The filtration fraction (FF) (i.e., the apparent fraction of the plasma cleared through the glomeruli) is given directly by the inulin/diodrast clearance ratio. The phenol red clearance (PR) has been followed in all observations, the data immediately above the phenol red clearance in the figures being the corresponding phenol red/diodrast clearance ratio. (For the significance of this ratio see the discussion of the action of phlorizin.) This ratio has not been corrected for the depression of the phenol red clearance by diodrast, which was present in the plasma in concentrations of 0.6 to $1.5 \mathrm{mgm}$. per cent. D, PR, and IN are expressed as cc. per 1.73 sq. m. per minute. These data and FF are plotted logarithmically, a convenient mode of expression since an equal variation up or down in any one of the variables represents an equal percentage change. Blood pressure (BP) was taken sphygmomanometrically. During acute phases of circulatory disturbance, the blood pressure was observed every two to three minutes, and at other times at intervals of five to ten minutes. The figures are recorded in $\mathrm{mm} . \mathrm{Hg}$. The rate of urine flow, $\mathrm{V}$, is given in cc. per minute.

Inulin, diodrast, and phenol red were given by constant intravenous infusion. The priming infusion consisted of 12 grams of inulin, $1.5 \mathrm{cc}$. of 10 per cent phenol red, and $1.5 \mathrm{cc}$. of 35 per cent diodrast solution in $100 \mathrm{cc}$. of 0.85 per cent saline, given at the rate of $10 \mathrm{cc}$. per minute. The sustaining infusion consisted of $\mathbf{4 5}$ grams of inulin, $10 \mathrm{cc}$. of phenol red, and $12 \mathrm{cc}$. of diodrast in $1000 \mathrm{cc}$. of saline, given at the rate of $4 \mathrm{cc}$. per minute. All details of technique were the same as those reported in the general description of methods given elsewhere (26).

\section{Water diuresis}

Figure 1 (Subject B. L., 1.83 sq. m., 52 per cent plasma) presents observations on the plasma flow and filtration rate during water diuresis in man. After three control periods, water was administered in four $250 \mathrm{cc}$. portions at five-minute intervals in order to minimize any disturbance of the systemic circulation. The urine flow, shown graphically, rose from $1.8 \mathrm{cc}$. to $14.2 \mathrm{cc}$. per minute. There was no change in the rate of glomerular filtration. The plasma flow decreased slightly, but there is no reason to believe that this circumstance was a result of the administration of water, or that it was causally related to the induction of diuresis. These observations are consonant with the evidence, which has been fully re- 


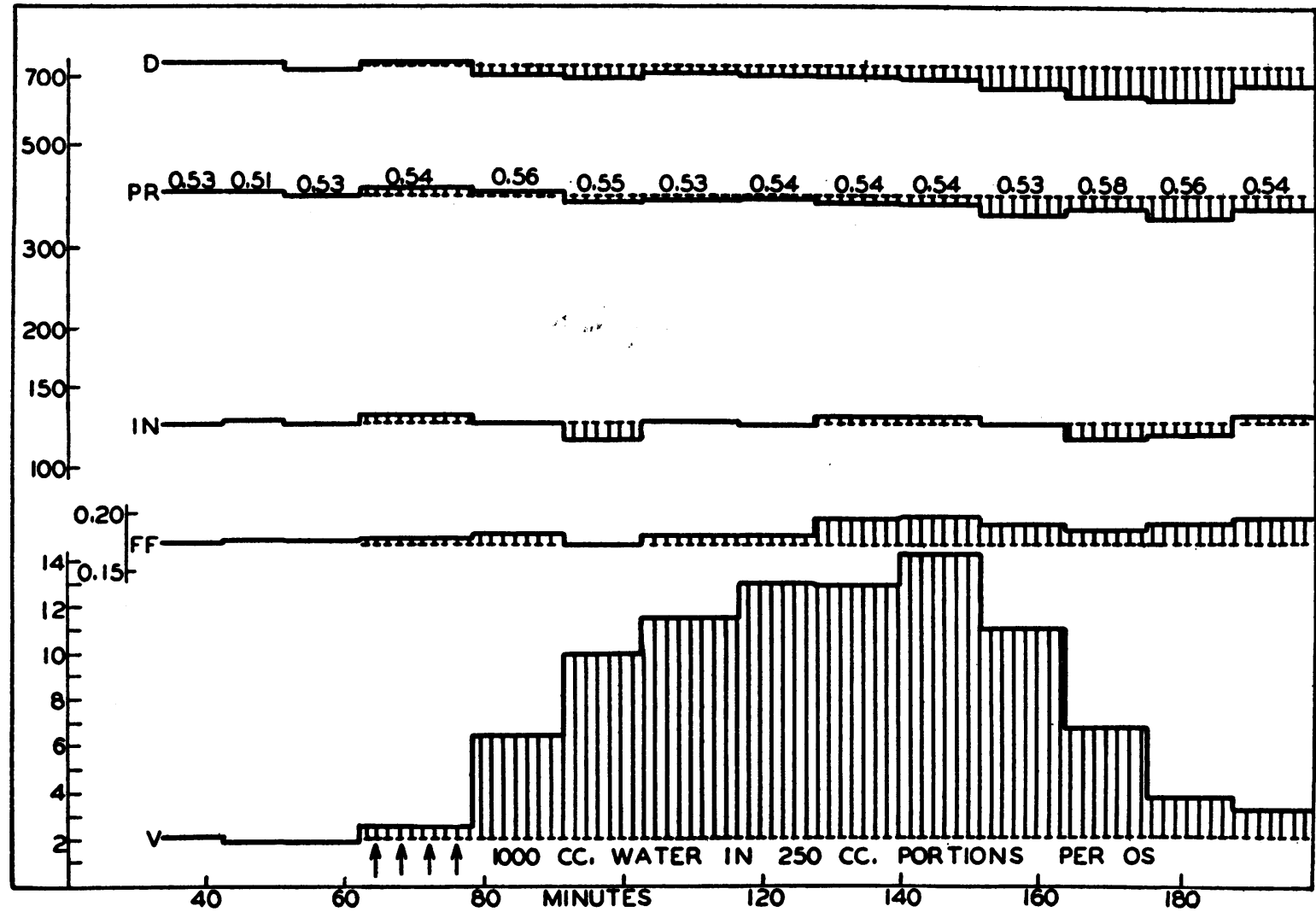

Fig. 1

Data on Subject B. L.

viewed elsewhere, that water diuresis is entirely referable to diminished tubular reabsorption and does not involve a change in renal blood flow or filtration rate (25).

\section{Oil of juniper}

(Figure 2, Subject R. D., 1.8 sq. m., 64 per cent plasma.) This and other essential oils once enjoyed a vogue as diuretics (1) and our examination was made with this fact in mind. In one instance, $0.2 \mathrm{cc}$. of oil of juniper was given orally, with no striking effect upon renal function except for a transient diuresis ( 2.3 to $6.3 \mathrm{cc}$. per minute). In the observations recorded in Figure 2 one cc. of oil of juniper increased the urine flow from 1.5 to $8.4 \mathrm{cc}$. (In this and subsequent figures the urine flow is recorded numerically at the bottom of the graph.) It is doubtful if the increase in plasma flow is physiologically significant, and the filtration rate and filtration fraction remained practically unchanged. In the absence of convinc- ing evidence to the contrary, the diuresis could well be attributed to a decreased excretion of the antidiuretic hormone, perhaps in consequence of a centripetal stimulus from the gastro-intestinal tract.

Figures 1 and 2 afford two series of control observations which, with numerous other instances that might be cited, warrant the conclusion that under basal conditions the plasma flow, filtration rate, and filtration fraction remain quite constant under continuous observation.

\section{Phlorizin}

(Figure 3, Subject J. C., 1.73 sq. m., 58 per cent plasma.) This glucoside produces inconstant but sometimes marked reductions in glomerular activity in all animals, and blocks the tubular reabsorption of glucose, xylose, and sucrose, and the tubular excretion of creatine and creatinine (25). Shannon (24) reported no reduction of the phenol red/inulin clearance ratio 


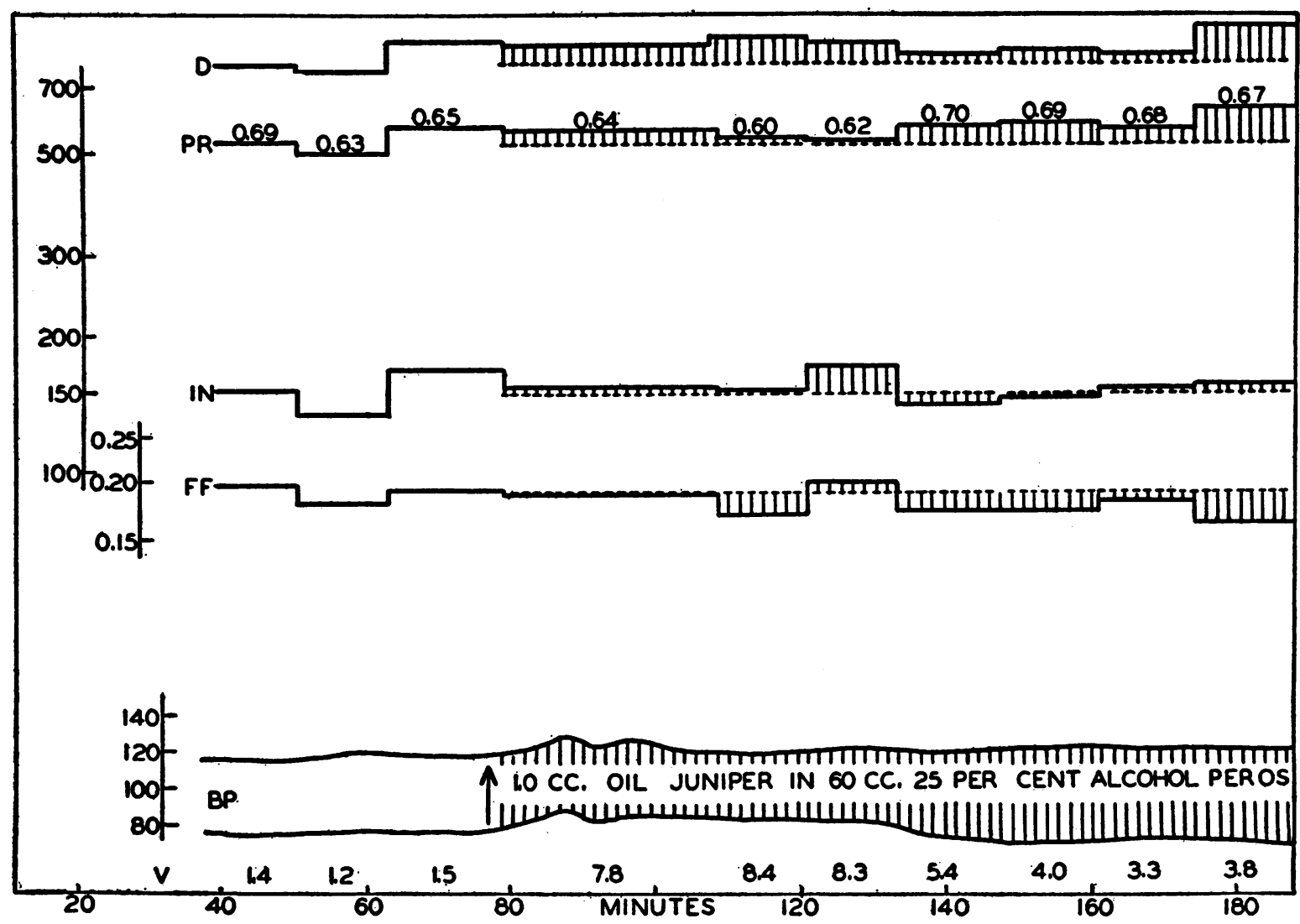

Fig. 2

Data on Subject R. D.

in the phlorizinized dog, but Pitts' data (18) suggest that the drug may have some action on the tubular excretion of phenol red in the chicken.

Our present observations demonstrate that, in man, phlorizin reduces the phenol red clearance to a much greater extent than the diodrast clearance, the excess reduction of the phenol red clearance being indicated in Figure 3 by the cross-hatched area. This fact indicates that the drug interferes with the tubular excretion of phenol red, and possibly also of diodrast. Since any clearance is acceptable as an index of renal plasma flow only so long as the renal $\mathrm{A}-\mathrm{V}$ extraction ratio remains constant, or very nearly so, it follows that the administration of phlorizin invalidates the use of the phenol red clearance, and throws grave suspicion on the use of the diodrast clearance for this purpose. The action of phlorizin raises the question of whether other physiologically reactive substances (adrenin, theophylline, etc.) may not simi- larly modify the extraction ratio of diodrast, and thus invalidate the clearance method of following the renal blood flow. This point is of such importance that it requires full discussion before applying this method further.

The data of Table II of our previous paper (26) gave the phenol red/diodrast clearance ratio in 6 normal subjects as 0.56 . Further data now available on 10 additional subjects leave this average at this figure, with the extreme variations of 0.46 to 0.73 . In general, the ratio is very constant in any one subject, as shown in Figures 1 and 2 , but there is a tendency for the ratio to fall when the diodrast clearance (plasma flow) is high, and to rise when the diodrast clearance is low. This same inverse relation is evident in individuals in whom renal ischemia ${ }^{1}$ or hyperemia

1 The term, "renal ischemia," is used here to denote any decrease in renal blood flow below normal, in line with the use of the term, "renal hyperemia," to denote any increase above normal. 


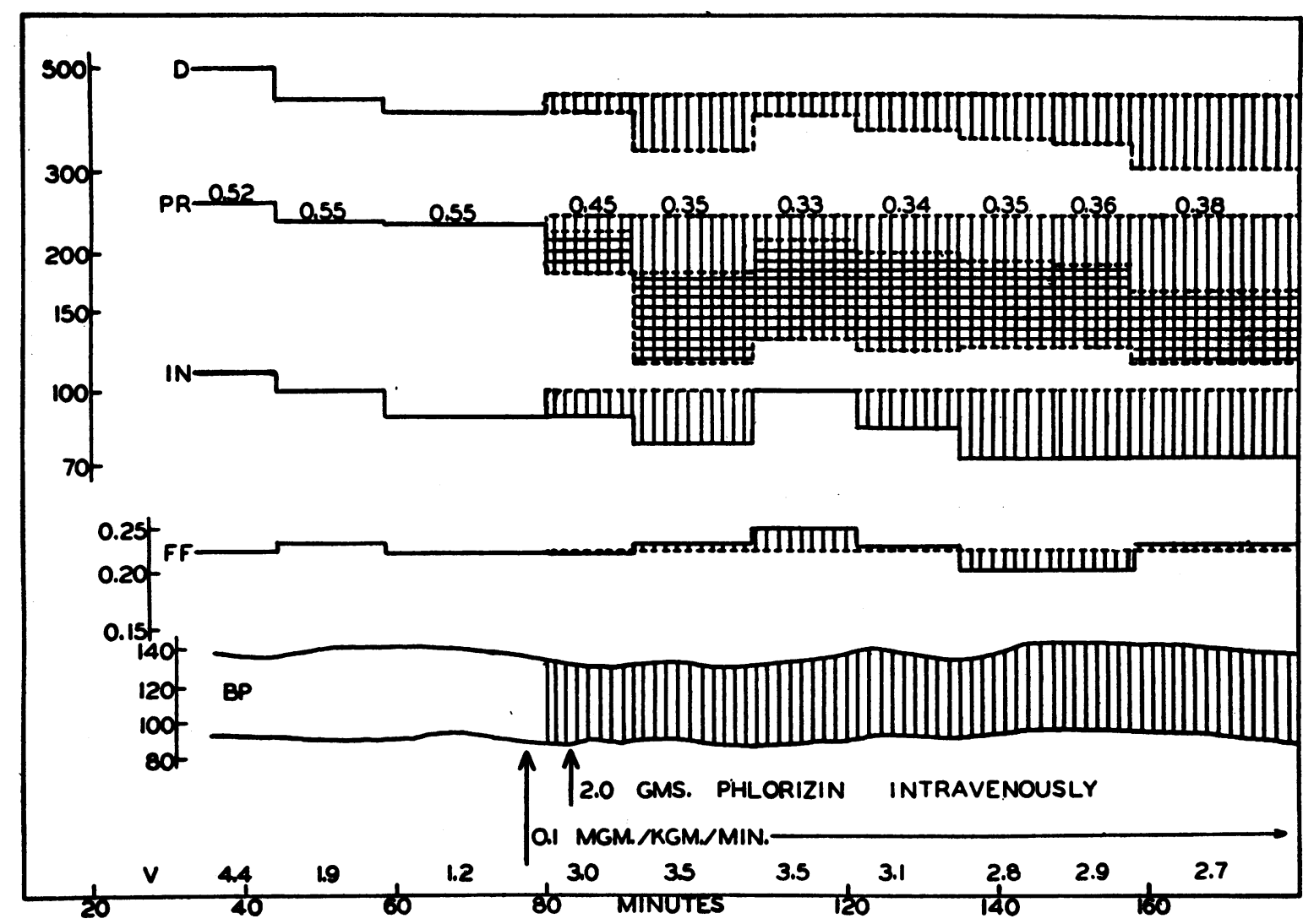

FIG. 3

Data on Subject J. C.

has been induced artificially. A further analysis of this phenomenon will be made subsequently, but an inverse relation between the phenol red/diodrast clearance ratio and the plasma flow is to be expected in theory for two reasons. First, increasing the renal blood flow increases the quantity of both phenol red and diodrast presented to the tubules per unit time; this circumstance would have little or no effect upon the diodrast clearance, since the extraction ratio of diodrast is independent at these low plasma concentrations of the rate of delivery to the tubules; but increased rate of delivery of either substance would cause some reduction in the extraction ratio of phenol red, since this is limited in part by concentration factors within the excretory mechanism itself, and consequently the phenol red clearance would not increase proportionally to the blood flow. Second, insofar as the phenol red extraction ratio is reduced below 100 per cent by the failure of phenol red to diffuse out of the peritubular capillaries in consequence of a reduction in diffusion gradient by protein-binding, or insofar as the ratio is reduced by temporal delay in the process of tubular excretion, prolongation of the renal circulation time would cause the extraction ratio to rise. The diodrast extraction ratio, being close to 100 per cent, would be affected to a lesser extent, and so long as the vascular bed remained constant the phenol red clearance would approach the diodrast clearance during renal ischemia and fall away from it during hyperemia. It may fairly be expected that, after the administration of a drug which brings about a change in renal plasma flow, the phenol red/diodrast clearance ratio should not deviate from its control value to a greater extent than is observed during equivalent changes in diodrast clearance in subjects who have received no medication.

On the other hand, if the tubular excretion of phenol red and diodrast has been impaired, or interfered with by a competitive solute, there are 
reasons to expect the phenol red clearance to be depressed to a greater extent than the diodrast clearance, in which case the clearance ratio would of course fall. We have previously shown that diodrast and hippuran, which have very high tubular clearances, have a marked depressive action on the phenol red clearance, while phenol red has but a slight depressive action on its own clearance or on the diodrast clearance (26). And it has been shown elsewhere that iopax and neoiopax likewise specifically depress the phenol red clearance more than they depress their own clearance (27). These relationships, which are quantitative, reversible, and reproducible, indicate that phenol red is a much more sensitive indicator of the presence of a solute which competes for the tubular mechanism than is diodrast. We now add to this list, phlorizin, which probably depresses tubular activity for reasons other than those that specifically limit the excretion of phenol red, diodrast, etc., when in competition for the normal mechanism of transfer. Here again the phenol red clearance is more sensitive to adverse action than is the diodrast clearance. It is, of course, conceivable that some drug may be found which depresses the diodrast and phenol red clearances in precisely the same degree, but in the absence of knowledge of such a substance, and in the light of the above observations, we believe that the phenol red/diodrast clearance ratio is a sensitive index of interference on the part of any agent (drugs, hormones, etc.) with tubular excretion, it being expected that such interference will be revealed by a fall in ratio when the diodrast clearance is decreased, contrary to the expectation that during a decrease in this clearance in consequence of true renal ischemia the ratio should rise. With the knowledge gained from the action of phlorizin and the other evidence cited, we are in a position to interpret the action of other substances with greater certainty.

The abnormal depression of the phenol red/ diodrast clearance ratio in Figure 3, invalidating as it does the use of both clearances as indices of plasma flow, leaves us in the position of being unable to say with any certainty what effect phlorizin has upon the renal circulation. The rise in the " apparent," filtration fraction is in keeping with the idea that the tubular excretion of diodrast has been slightly impaired. The action of phlorizin has been examined in one other individual, with results qualitatively the same as those shown in Figure 3.

\section{Adrenin}

(Figure 4, Subject P. V., 1.7 sq. m., 57 per cent plasma.) In 1922 Richards and Plant showed that when the perfused rabbit kidney is supplied with blood at a constant rate of flow, adrenin causes a rise in the perfusion pressure and at the same time swelling of the kidney, an observation confirmed in eviscerated rabbits and dogs (21, 22). Richards and Plant interpreted the paradox of simultaneous vasoconstriction with renal expansion by suggesting that adrenin acts preferentially to constrict the efferent arterioles, thus causing distension of the glomerular and preglomerular vessels. This interpretation has been affirmed by Winton $(35,36)$ from observations on the heartlung-kidney. Thermostromuhr measurements on anesthetized, decerebrate dogs show that adrenin consistently reduces the renal blood flow $(10,28$, 31 ), though the threshold of the renal vessels in such animals is about 100 times as high as the threshold of the vessels of the muscles and skin (10).

We believe that observations on such preparations as are discussed above should be transferred to the normal organism with caution. However, in this specific instance, our observations on normal man are in agreement with the conclusions reached from the above evidence. As seen in Figure 4, $1 \mathrm{mgm}$. of adrenalin given subcutaneously, with massage for two or three minutes immediately afterwards, caused a reduction in plasma flow from $680 \mathrm{cc}$. (1192 cc. of whole blood) to a minimum of $373 \mathrm{cc}$. ( $654 \mathrm{cc}$. of whole blood) per minute. The filtration fraction increased from 16 per cent to a maximum of 29 per cent. If the reduction in plasma flow were owing to constriction of the afferent arterioles or of vessels proximal to these, it is to be expected that this constriction would reduce the effective glomerular pressure and therefore the filtration fraction, and a reduced filtration fraction and reduced plasma flow would lead to a reduction in the filtration rate. But if constriction occurs at the efferent arterioles (with or without dilatation of the efferent arteri- 


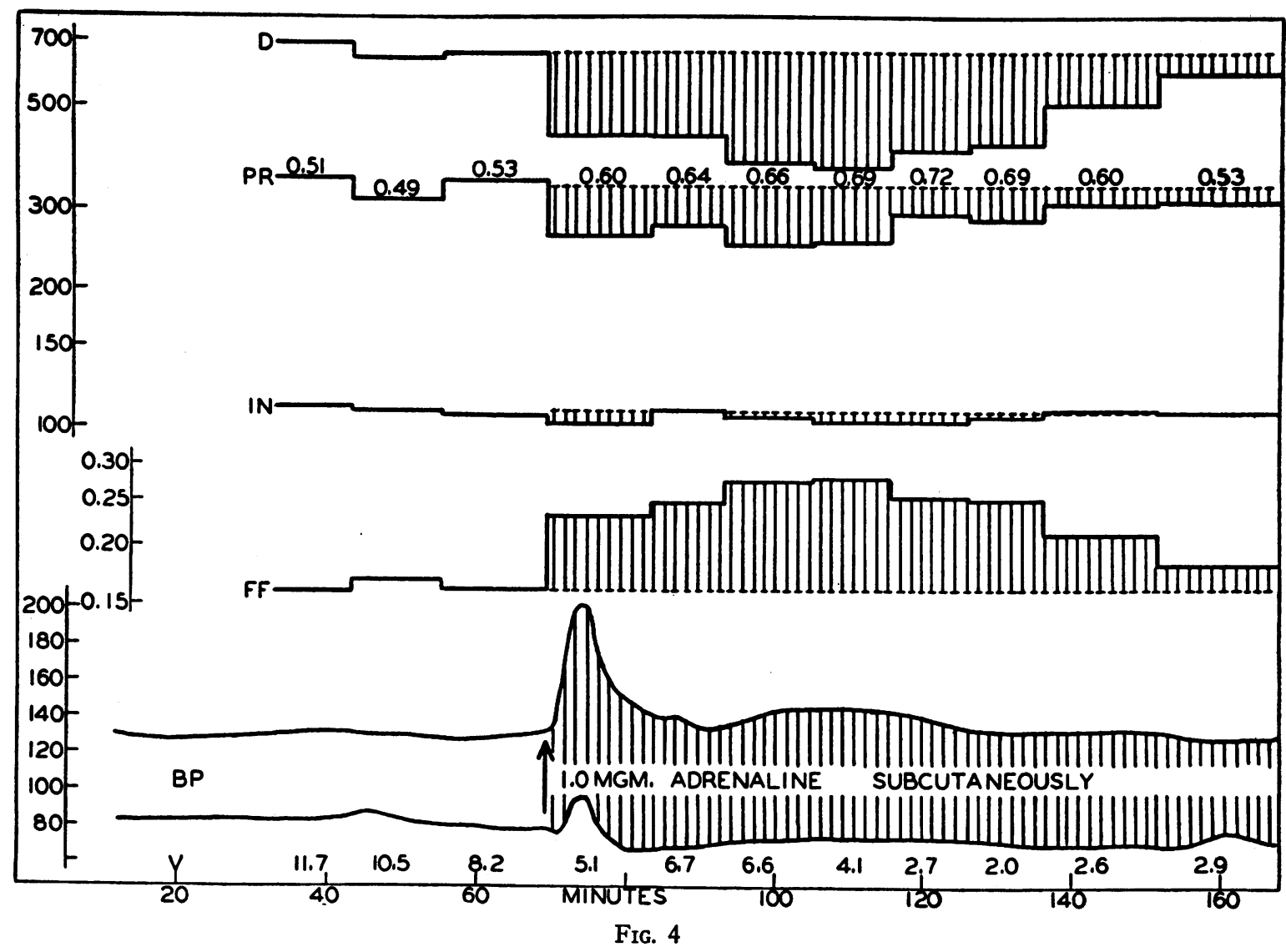

Data on Subject P. V.

oles), ${ }^{2}$ it is to be expected that the effective glomerular pressure, and therefore the filtration fraction, would be raised more or less pari passu with the reduction in plasma flow; the increased filtration fraction would tend to offset the decreased plasma flow and to maintain the filtration rate at

2 Though the point is not established, one presumes that equilibrium between filtration pressure and the opposing osmotic pressure of the plasma proteins and the capsular pressure is reached by the time the plasma emerges from the glomeruli. If equilibrium is not reached, then, of course, the time during which the plasma remains in the glomeruli, and therefore the volume of the glomerular capillaries and the rate of blood flow, must be considered along with the filtration pressure as determinants of the filtration rate. This consideration would not, however, alter the above statement.

It appears unnecessary to postulate that adrenin dilates the afferent arterioles, as does Winton (36). If the osmotic pressure of the plasma proteins is taken to be $25 \mathrm{~mm}$. $\mathrm{Hg}$ and this is raised by filtration to $30 \mathrm{~mm}$., and if the capsular pressure is taken to be $15 \mathrm{~mm}$., the total pressure opposing filtration will be $45 \mathrm{~mm}$. Taking a constant level. The action of adrenin is wholly consonant with the latter view.

There appears to be only one alternative to the above interpretation: if glomerular hemodynamics and the permeability of the glomerular membranes are such that a rigidly constant volume of fluid is filtered per unit time, regardless of glomerular pressure, then of course the filtration rate will re-

the mean normal glomerular pressure as 60 per cent of the mean arterial pressure, the effective filtration pressure in the above subject would be $66-45$ or $21 \mathrm{~mm}$. Under the action of adrenin the emergent blood would have an oncotic pressure not exceeding $38 \mathrm{~mm}$; at a constant filtration rate, and therefore a constant capsular pressure, the total pressure opposing filtration would be $38+15$ or $53 \mathrm{~mm}$. Taking the mean glomerular pressure as 90 per cent of the mean arterial pressure, the effective filtration pressure would be increased to $99-53$ or $46 \mathrm{~mm}$., enough to double the filtration fraction. An increase of 100 per cent is the largest we have observed in the normal subject before and after the administration of the adrenin. 
main constant and independent of plasma flow, and the filtration fraction will vary inversely as plasma flow. This alternative explanation, however, is very suspect. First, it is not in harmony with the evidence that the separation of capsular fluid in the glomeruli is effected by an unconditioned process of filtration, rather than by a conditioned process of transudation, and this is too substantial to be lightly rejected (25). Any membrane which conditions the rate of passage of water regardless of hydrostatic pressure must, we believe, possess differential permeability to the electrolytes and other constituents of the plasma. Second, the alternative explanation is contrary to the fact that the filtration rate does, under certain circumstances, increase or decrease through a range of -50 to +100 per cent (see also Figures 3,5 , and 6 ).

We therefore reject the alternative explanation, and present the data in Figure 4 as substantiation of Richards and Plant's thesis for the normal human kidney $(21,22)$. These data further demonstrate that, in the normal kidney, the degree of efferent arteriolar tone, and therefore the effective filtration pressure, are submaximal and can be caused to approach maximal values by adrenin. Presumably sympathetic activity has this same action on the efferent arterioles. ${ }^{8}$

During the period of renal ischemia the phenol red/diodrast clearance ratio rises above its control values, as is to be expected in theory; the fact that this ratio is not reduced during the period of ischemia is evidence that adrenin has not specifically impaired the excretory activity of the tubules, and that the diodrast clearance is a valid indication of changes in blood flow.

It has been our experience and the experience of others that adrenin may cause a marked oliguria. It is quite possible that this oliguria is central in origin, i.e., release of antidiuretic hormone from the pituitary gland, since Rydin and

\footnotetext{
8 The rise in blood pressure immediately after the injection of adrenin is, in this instance, exaggerated by the massage used to facilitate absorption. In other cases, this pressure rise has been less marked. It is typical of the action of moderate doses of adrenin in man that, while the systolic pressure is slightly increased, the diastolic pressure is reduced. It would seem that this is caused by the reduction of the mean peripheral resistance by dilatation of the skeletal muscle and coronary arteries, simultaneously with an increase in the cardiac output.
}

Verney (23) have shown that the inhibition of water diuresis which is associated with emotional stress and exercise is explicable on this basis. In anticipation of oliguria, the observations in Figure 4 were made on the descending limb of water diuresis, and 2.0 per cent $\mathrm{Na}_{2} \mathrm{SO}_{4}$ was incorporated in the infusion fluid in order to maintain the urine flow. For this reason the data on urine flow have no special significance.

The action of adrenin has been examined in five other subjects with results qualitatively similar to those given in Figure 4. One of the most notable features in the action of this hormone is that the filtration rate remains remarkably constant in spite of relatively great changes in renal plasma flow. This has been noted in every subject examined, and it suggests an important reciprocal relation between the diameter of the lumen of the efferent arterioles, the blood flow, and the effective glomerular pressure. If the renal blood flow is controlled primarily by variations in the efferent arteriolar tone, wide variations in this tone would leave the filtration rate relatively unchanged.

\section{Theophylline and caffeine}

(Figure 5, Subject B. L., 1.83 sq. m., 55 per cent plasma.) Caffeine causes an increase in the number of active glomeruli and engorgement of the glomerular vessels of the amphibian kidney when the latter is exposed for microscopic examination (25), but such observations do not have a conclusive bearing on the action of the drug in the mammalian kidney; with the exception of the rabbit, normal glomerular activity appears to be more constant and more nearly maximal in the mammals than in the lower vertebrates $(6,25)$.

The widespread opinion that caffeine and other purine derivatives typically induce hyperemia in the mammalian kidney rests upon four methods of observation: measurements of arterial or venous flow by a mechanical stromuhr, measurements of the size of a kidney by the oncometer, measurements of the rate of flow in the perfused heartlunig-kidney, and measurements of blood velocity by a thermostromuhr attached to the renal artery or vein in an anesthetized or conscious animal. (For the early literature on this subject see 2 and 4.) Methods involving the use of perfused kidneys or eviscerated, anesthetized animals can be 


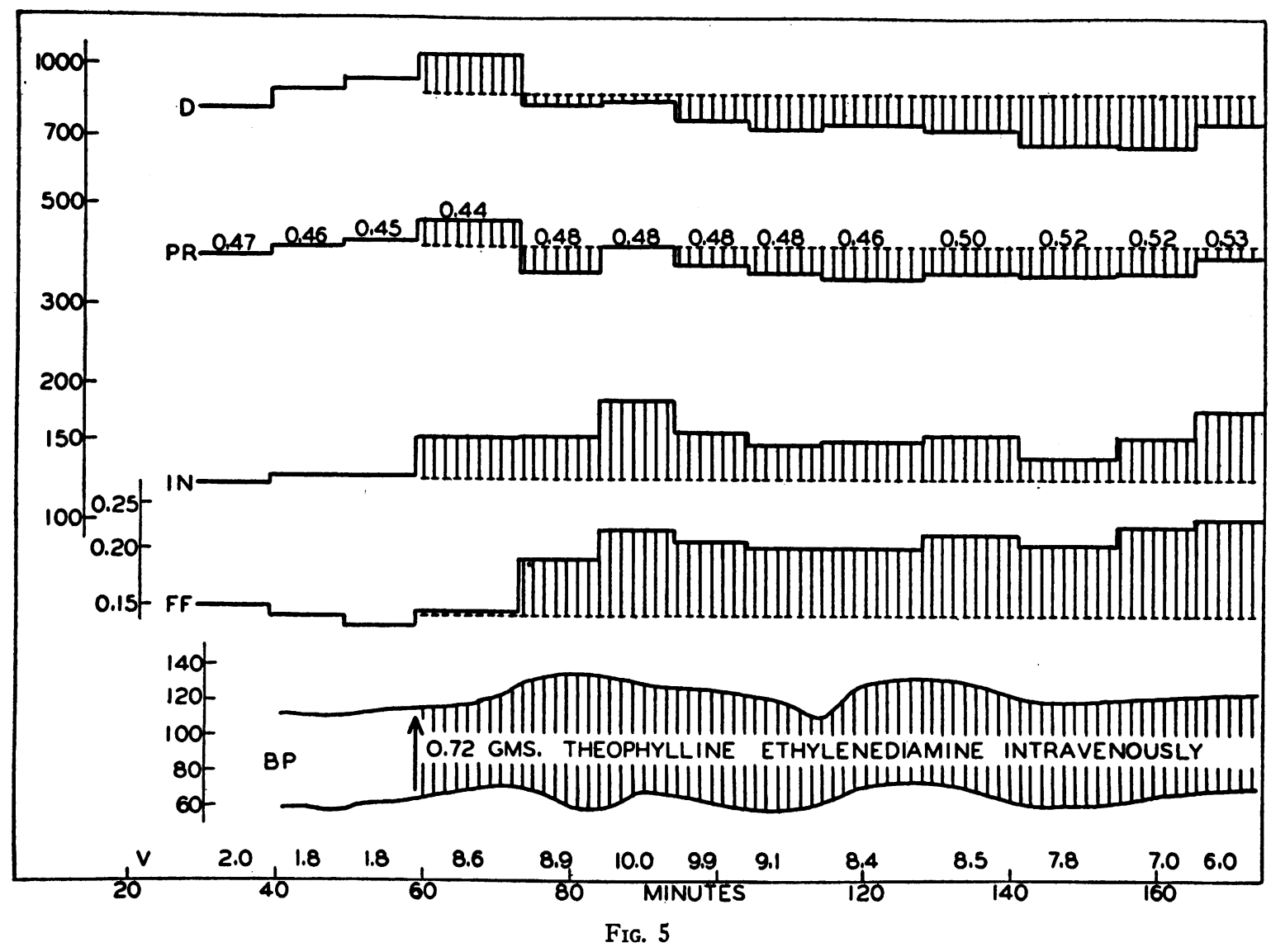

Data on Subject B. L.

held to have only a remote bearing upon the normal organism. By the oncometer it is impossible to distinguish enlargement of the kidney caused by vasodilatation, diuresis, or glomerular distension $(2,21,25)$. Gremels (8) occasionally, and Verney and Winton (32) almost invariably, obtained an increase in the perfusion rate of the heart-lung-kidney after the addition of caffeine, theophylline, etc. It is known, however, that the heart-lung-kidney is definitely unphysiological; normal, concentrated urine cannot be obtained, and at a constant perfusion pressure the blood flow may increase spontaneously 100 per cent in consequence of changes in the tonus of the renal vessels (7). Shed blood rapidly develops powerful vasoconstrictor power (12): these " vasotonins" are supposed to be removed by perfusion through the lungs $(3,11,29)$, yet when a freshly isolated kidney is perfused by the animal's own circulation vasotonic substances are given off into the systemic blood (5). One may on the above evidence question the basal vasomotor tone and the responses to drugs of the heart-lung-kidney. The same criticism applies to the pump-kidney (17). Using a thermostromuhr applied to the renal artery of anesthetized dogs, Janssen and Rein (14) obtained renal hyperemia after $3 \mathrm{mgm}$. per kgm. of caffeine per os, but the details of their experiments showing how long the hyperemia lasted are not available, and the observation needs confirmation on unanesthetized and untraumatized animals. The only available observations on unanesthetized animals are those of Walker, Schmidt, Elsom, and Johnston (33), which were made by a thermostromuhr applied to the abdominal aorta of rabbits with suitable ligations to restrict the blood flow to one kidney. The observations were made a few hours after operation. These investigators found that theophylline injected intravenously in doses of $12 \mathrm{mgm}$. produced, in seven out of ten experiments, an increased blood flow which was, however, transient, lasting on the average only 9 
minutes. Thereafter, the blood flow returned to or below its former level. In two of the four experiments which these investigations report graphically the blood flow was at a reduced level after the administration of the drug. But again we call attention to the uncertainty of transferring observations on glomerular hemodynamics from the rabbit to the dog or man.

From the above, it will be seen that there is no certain evidence on which to conclude that xanthine derivatives in therapeutic doses induce renal hyperemia in the normal animal. On the contrary, we conclude from a study of the diodrast clearance that theophylline and caffeine consistently reduce the blood flow through the normal human kidney. In the observations recorded in Figure 5, 0.72 gram of theophylline ethylenediamine given intravenously reduced the diodrast clearance from its mean control value of $875 \mathrm{cc}$. per minute to a minimal value of $670 \mathrm{cc}$. per minute. Simultaneously, the filtration rate was increased from 123 to a value above $150 \mathrm{cc}$., and the filtration fraction increased from 14.2 per cent to a value above 20 per cent. After the administration of theophylline the phenol red/diodrast clearance ratio, if it changed significantly, increased, as is to be expected during a period of renal ischemia. From this fact we feel confident that the reduction of the diodrast clearance is not due to an interfering action of the drug upon the excretory activity of the tubules, but to an actual reduction in plasma flow.

We have examined the action of theophylline in four other instances, and the action of caffeine sodium benzoate in two instances. Theophylline ethylenediamine was given intravenously in doses of $0.96,1.05$ and 1.2 grams, and once by constant intravenous infusion at the rate of $17 \mathrm{mgm}$. per minute. Caffeine sodium benzoate was given subcutaneously in a dose of $450 \mathrm{mgm}$., and a half hour later an additional dose of $450 \mathrm{mgm}$. was injected intravenously. On another occasion 300 mgm., which is essentially a minimal effective dose so far as cerebral effects are concerned, were given orally. In every case, the results were qualitatively the same as those shown in Figure 5, except that with larger doses the reduction in plasma flow and increase in filtration fraction were much more marked. The largest doses of theophylline decreased the plasma flow from $450 \mathrm{cc}$. to a mini- mum of $255 \mathrm{cc}$, and raised the filtration fraction from 17.5 per cent to a maximum of 35 per cent; $300 \mathrm{mgm}$. of caffeine decreased the plasma flow from 630 to $540 \mathrm{cc}$. per minute and increased the filtration fraction from 18 to 22 per cent.

The xanthine derivatives increase the cardiac output and decrease the peripheral resistance (13, $15,30)$, showing that they dilate some arterioles in normal man; it may be that they dilate the afferent glomerular arterioles and thus contribute to the elevation of filtration pressure effected by efferent constriction. This would explain the circumstance that the filtration rate, which is relatively unaffected by adrenin, may in some instances be markedly increased by theophylline and caffeine, as in Figure 5 ; and, if afferent dilatation preceded efferent constriction in time, it would explain the fact that in three instances, including the subject reported in Figure 5, the renal plasma flow was increased during the first period after the administration of the drug. But if afferent dilatation occurs, it is overshadowed by efferent constriction with, in the mean, a reduction in renal blood flow.

Whether the xanthine derivatives act locally upon the renal vessels or through the central nervous system is not known.

The diuretic action of these compounds is notoriously uncertain. In the observations recorded in Figure 5 the urine flow rose from $1.8 \mathrm{cc}$. to a maximum of $9.9 \mathrm{cc}$. Here, and in some other instances, the increased urine flow is correlated with an increased filtration rate, but evidence has been presented that this is not the essential mechanism of xanthine diuresis (25). In interpreting this diuresis the possible influence of these substances upon the central nervous system and the nervous control of the pituitary gland must not be overlooked.

\section{Typhoid vaccine pyrexia}

(Figure 6, Subject D. W., 1.63 sq. m., 58 per cent plasma.) We have noticed during the course of the reaction elicited by pyrogenic infusions that the renal plasma flow may rise to values considerably above normal. Since pyrexial reactions induced by the intravenous injection of vaccines of the typhoid group are widely used in the therapy of chorea, thrombo-angiitis obliterans, and other diseases, we present in Figure 6 what seems to be 


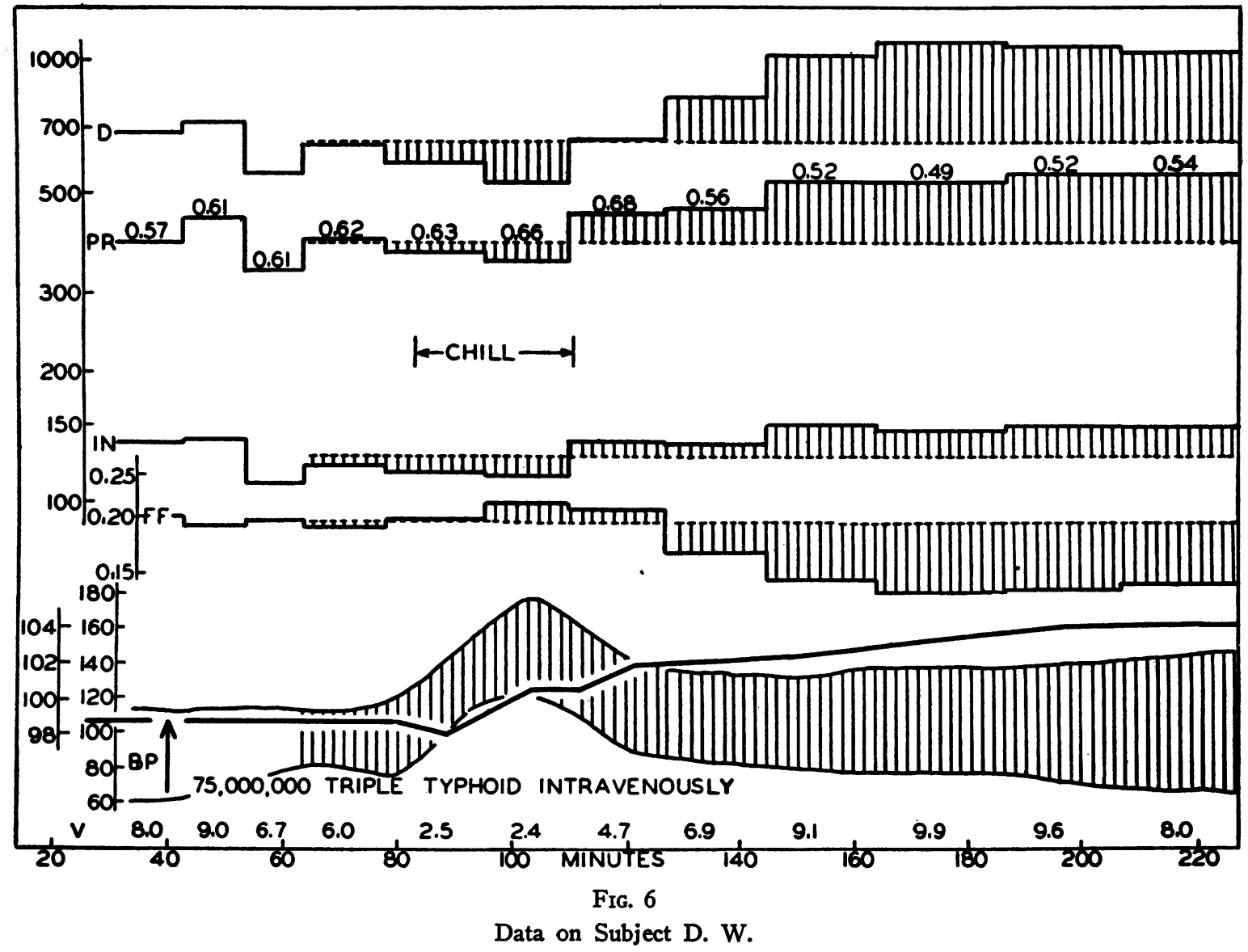

a fairly typical reaction. ${ }^{4}$ The signs of reaction are lacking during the first thirty minutes or so after the injection of the vaccine, and this interval in Figure 6 may be taken as a control period. The first objective sign appears generally to be a distinct rise in the diastolic and then the systolic pressure; shortly afterwards the subject begins to feel chilly, or experiences a definite chill, with headache, nausea, and malaise. The rise in blood pressure reaches its peak during the chill, and as the pressure falls the pulse rate and temperature (the solid line in Figure 6) begin to rise.

Ranson (19), reviewing the literature and discussing typhoid pyrexia in cats, suggests that the reaction consists of alternate stimulation of the sympathetic mechanism promoting conservation of heat, and then of the parasympathetic mechanism promoting heat loss. Probably the antago-

$\leqslant$ Three-hundredths cc. of a mixture containing one billion $B$. typhosus and seven hundred and fifty million each of $B$. paratyphosus $\mathrm{A}$ and $\mathrm{B}$ per cc. nistic mechanisms are stimulated simultaneously, first one and then the other predominating. In the cat, the phase of rising temperature is accompanied by excitement, dilatation of the pupils, cutaneous vasoconstriction, and occasionally erection of hair, while the phase of falling temperature is accompanied by pupillary constriction, cutaneous vasodilatation, defecation, and occasional urination and penile erection.

Our observations show that at the onset of the rise in blood pressure the renal plasma flow is decreased and the filtration fraction is increased, indicating efferent arteriolar constriction (sympathetic activity). The decrease in renal plasma flow is sometimes more marked than in the data shown in Figure 6. After the blood pressure has reached its peak and started to fall, the renal ischemia gives way to hyperemia, and the filtration fraction falls to subnormal levels. The average plasma flow in the first three periods in Figure 6 was $693 \mathrm{cc}$. (1195 cc. of whole blood), the minimal 
plasma flow, 535 cc. (922 cc. of whole blood), and the maximal plasma flow $1085 \mathrm{cc}$ (2045 cc. of whole blood), 71 per cent above the control level. Grollman (9) has shown that there is a marked increase in the cardiac output when typhoid vaccine is given subcutaneously, and a similar increase probably occurs here and makes possible a renal hyperemia of this magnitude. However, it must be noted that this hyperemia is not to be explained wholly by either increased cardiac output or dilatation of the afferent arterioles. Neither factor could operate alone to produce hyperemia without increasing the glomerular pressure and therefore the filtration fraction; the fact that the hyperemia is accompanied by a fall in the filtration fraction demonstrates that efferent dilatation is a major factor, whatever the contributions of increased arterial pressure and afferent dilatation. Whether or not afferent dilatation is present cannot be said, nor can a quantitative appraisal be given at the present time to the increased arterial pressure. But if these factors are functionally significant, they must operate in the direction of maintaining the filtration pressure and the filtration fraction at levels higher than would otherwise obtain.

Apart from the recorded data, the only signs of autonomic activity which we have noted are peripheral vasoconstriction during the chill, as indicated by a fall in the temperature of the toe, and marked rectal stimulation during the height of the fever. But our results are in keeping with the conclusion of Ranson that there is alternation of sympathetic and parasympathetic activity during the prefebrile and febrile phases of the pyrexial reaction. Whether dilatation of the efferent glomerular arterioles is an invariable concomitant of parasympathetic activity cannot be said.

In the evaluation of these observations it must be recognized that the elevation of body temperature $\left(+6^{\circ} \mathrm{F}\right.$.) probably increased to some degree the specific excretory activity of the renal tubules; if so, and if the diodrast extraction ratio is less than 1.0 during the control periods, this ratio may rise towards 1.0 during the fever, and thus contribute to the increased clearance. It is, however, quite unlikely that an increase of 70 per cent in the diodrast clearance can be explained on this basis; moreover, the phenol red/diodrast clearance ratio falls during the fever, as is to be expected in consequence of an increased velocity of blood flow.

Our observations on pyrexia indicate that the renal blood flow is normally limited by tonic constriction of the efferent glomerular arterioles, which also serves to maintain the filtration pressure at a relatively high level. This tonic constriction is released during the febrile phase of the reaction. To what extent the elevation of systemic pressure or dilatation of the afferent glomerular arterioles contributes to the renal hyperemia is undetermined, but if these are not given much weight it appears that within certain limits there is a reciprocal relationship between blood flow and filtration pressure such as to maintain the filtration rate at a relatively constant value.

\section{Sodium nitrite}

(Figure 7, Subject R. D., 1.80 sq. m., 65 per cent plasma.) Wilkins, Haynes, and Weiss (34) have shown that sodium nitrite acts predominantly by dilating the venous system and reducing the venous pressure; the consequent reduction of the arterial pressure, acting through the carotid sinus, induces vasoconstriction of the peripheral arterioles. The resulting circulatory picture closely resembles the early stages of shock, prior to vasomotor collapse. Although Starr et al. (30) find that the cardiac output is slightly increased with oral doses of 0.14 gram of sodium nitrite, it must be supposed that in circumstances such as those obtaining in Wilkins, Haynes, and Weiss' observations, and in the observations reported here, the cardiac output is appreciably reduced by the reduction of venous pressure.

We have administered amyl nitrite by inhalation and sodium nitrite by continuous intravenous infusion, the latter technique proving to be amenable to better control. In the observations given in Figure 7, the stronger infusion reduced the blood pressure but caused no circulatory disturbances in the recumbent position except an increase in heart rate. When, at the conclusion of the last period, the subject was raised in bed to 45 degrees, the blood pressure fell to $66 / 44$ and he complained of vertigo, demonstrating circulatory inadequacy. The plasma flow and filtration rate were decreased, the latter to a slightly greater extent. In the last 


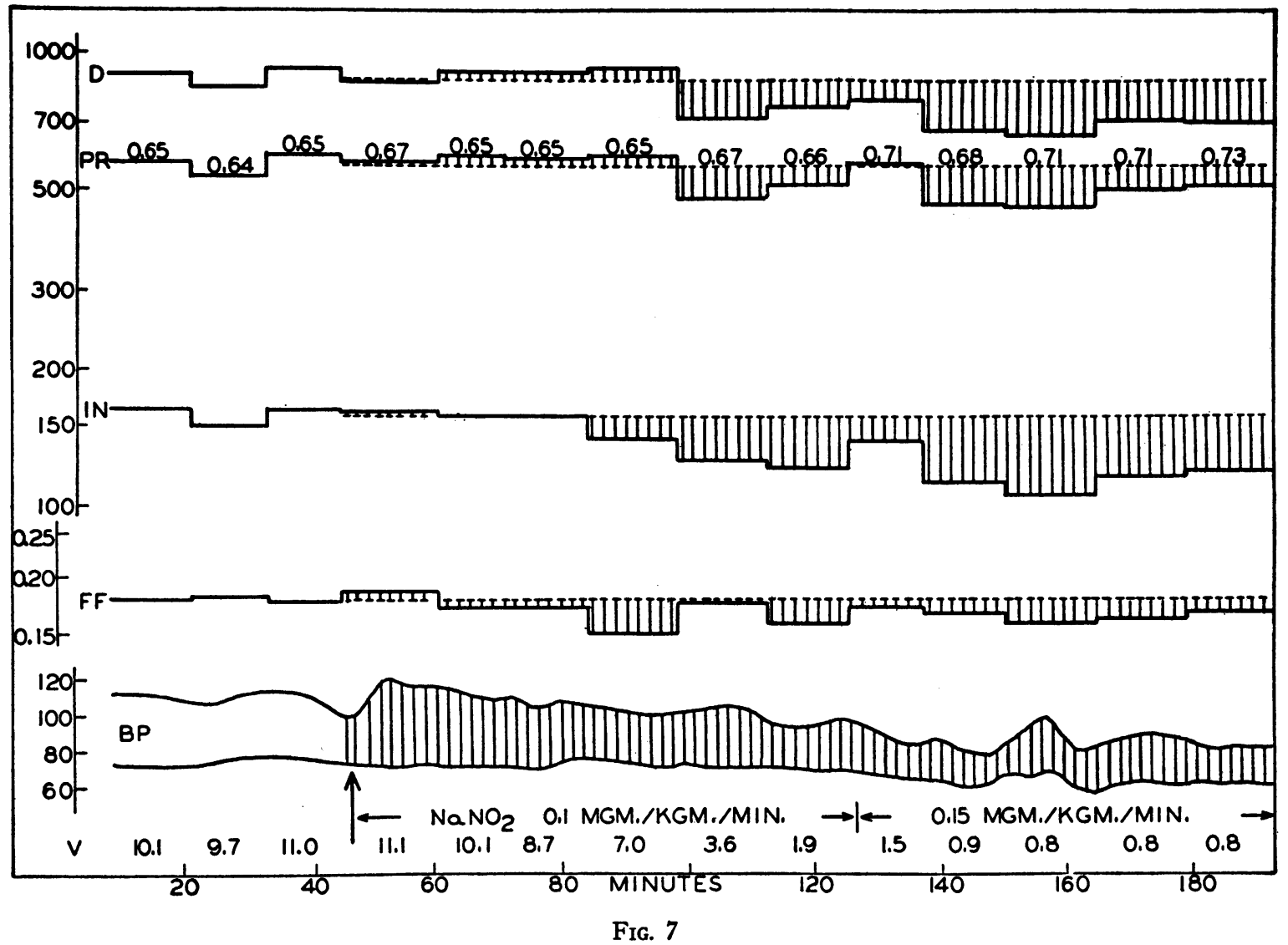

Data on Subject R. D.

few periods there was marked oliguria, perhaps attributable to the reduced filtration rate. The phenol red/diodrast clearance ratio rose slightly as the plasma flow was reduced, indicating that the drug did not impair tubular activity.

Observations of the above type have been made in three other subjects; once sodium nitrite was infused at a rate of 0.05 , once at 0.042 , and once at $0.05-0.1 \mathrm{mgm}$. per $\mathrm{kgm}$. per minute. In all cases the results have been qualitatively similar to those shown in Figure 7, although the sensitivity of different individuals appears to vary considerably.

Perhaps the most significant feature of the action of nitrites is the absence of evidence of renal participation in the vasomotor responses induced by this drug. Efferent arteriolar constriction would elevate the filtration fraction, afferent constriction would reduce this fraction, while simultaneous constriction on both the efferent and afferent side might leave the filtration fraction un- changed. The latter is the only possibility that accords with our data. But in view of the fact that there is a reduction in systemic pressure adequate to account for the observed slight reduction in renal blood flow, it appears unnecessary to suppose that such simultaneous constriction occurs. The slight reduction in renal blood flow coupled with a slight reduction in filtration fraction, also attributable to the decreased systemic pressure, leads to a reduction in filtration rate. Our results are consonant with the conclusions of Wilkins, Haynes, and Weiss that nitrite acts predominantly on the venous system.

\section{DISCUSSION}

The observations described above afford a basis for the semiquantitative description of renal blood flow and glomerular hemodynamics in the normal human kidney. The renal blood flow appears to be quite constant in any one individual under basal conditions. That the efferent arteri- 
oles are not normally constricted to a maximal extent is demonstrated by the fact that at an essentially constant arterial pressure adrenin causes a decreased blood flow and an increased filtration fraction. That the efferent arterioles are not normally dilated to a maximal extent is demonstrated by the fact that during the pyrexia induced by typhoid vaccine, the renal blood flow is increased while the filtration fraction falls. It may be inferred, without excluding the possibility of changes in afferent tone, that physiological changes in renal blood flow are mediated primarily by changes in efferent arteriolar tone.

Accepting the thesis that the fraction of plasma filtered through the glomeruli is roughly proportional to the effective filtration pressure in the glomeruli (i.e., the hydrostatic pressure-oncotic pressure and capsular pressure), it follows from the circumstance that the control of renal blood flow is on the efferent side of the glomeruli, that this filtration fraction will increase as the renal blood flow is decreased, and decrease as the renal blood flow is increased; and, therefore, that the filtration rate will tend to remain constant in spite of wide variations in renal blood flow. Were the renal blood flow controlled on the afferent side of the glomeruli, the filtration pressure would increase during renal hyperemia and decrease during renal ischemia, and therefore the filtration rate would vary in the same direction and as some power of the blood flow. We suggest that the notable constancy of the filtration rate in any one individual and in different individuals (26) is attributable in large part to the hemodynamic relationships which issue from the predominance of efferent over afferent arteriolar tone.

Thirty-four observations on fifteen normal subjects indicate an effective renal blood flow ranging from 1050 to $1680 \mathrm{cc}$., or 595 to $916 \mathrm{cc}$. of plasma, and average $1339 \mathrm{cc}$. and $772 \mathrm{cc}$. respectively, per 1.73 sq. m. per minute. The filtration fraction ranges from 15.3 to 21.8 per cent, and averages 17.7 per cent. This series is not large enough to treat statistically at the present time and will be expanded as opportunity permits.

For the sake of completeness, we may relate briefly the above facts to the excretion of water. The maximal urine flow, which ranges from 8 to 21 cc. per minute in different individuals, is de- termined by the circumstance that a large fraction of the water in the glomerular filtrate is reabsorbed by the tubules under all conditions (see obligatory reabsorption (25) p. 231). The minimal urine flow (about $0.3 \mathrm{cc}$. per minute in the normal subject) is determined by the opposition which the urinary constituents offer to the reabsorption of the water. Variations in urine flow between these extremes (facultative reabsorption) are, at least in part, controlled by the antidiuretic hormone of the posterior pituitary gland. Since the secretion of this hormone is variable, and since numerous factors in the composition of the urine modify the maximal reabsorption of water, variations in urine flow rarely reflect variations in renal blood flow, filtration fraction, or absolute filtration rate.

Observations on the dog indicate that the renal vascular bed does not participate in the vasomotor reflexes which are concerned with the maintenance of arterial pressure, and which are mediated through the carotid sinus $(16,20,31)$. Such an interpretation might be placed upon our failure to find evidence of vasomotor response in the kidneys during the action of nitrite, but the question whether the renal circulation in man enjoys complete isolation from the carotid sinus reflexes cannot be answered without further examination. It may be anticipated that the reflex pattern in man will differ in significant respects from the pattern in the dog, since in the human pattern postural reflexes and the regulation of heat loss through the skin play rather more important rôles.

\section{SUMMARY}

The diodrast, phenol red, and inulin clearances have been followed in normal man during a variety of experimental conditions. Evidence is presented that so long as the phenol red/diodrast clearance ratio varies inversely with the absolute clearances, it can be assumed that tubular activity is normal and that the clearance method of measuring the effective renal blood flow is valid.

Data are presented which throw light on the physiological regulation of the renal blood flow and the rate of glomerular filtration. These data are drawn from observations on water diuresis and the action of oil of juniper, adrenin, theophylline, caffeine, and sodium nitrite, and during the py- 
rexial reaction induced by the intravenous administration of typhoid vaccine.

The renal blood flow appears to be controlled predominantly by the efferent glomerular arterioles, these arterioles being normally partially constricted. Since, with such efferent control, an increase or decrease in renal blood flow is accompanied by an inverse change in filtration pressure, the filtration fraction varies inversely to, and the filtration rate tends to be independent of, the renal blood flow.

\section{BIBLIOGRAPHY}

1. Cow, D., Einige Studien über Diurese. Arch. f. exper. Path. u. Pharmakol., 1912, 69, 393.

2. Cushny, A. R., The Secretion of the Urine. Longmans, Green \& Co., New York, 1917.

3. Eichholtz, F., and Verney, E. B., On some conditions affecting the perfusion of isolated mammalian organs. J. Physiol., 1924, 59, 340.

4. Ellinger, P., Die Absonderung des Harns unter verschiedenen Bedingungen einschliesslich ihrer nervösen Beeinflussung und der Pharmakologie und Toxikologie der Niere. Vol. IV. Handb. d. Norm. u. Path. Physiol., 1929, 308-450.

5. Enger, R., and Gerstner, H., Der Einfluss der Niere auf den Blutdruck nach ihrer völligen Lösung aus dem Gewebszusammenhang des Organismus. Ztschr. f. d. ges. exper. Med., 1938, 102, 413.

6. Forster, R. P., Xylose, inulin and creatinine clearance in the normal frog. Proc. Soc. Exper. Biol. and Med., 1938, 38, 258.

7. Gelfan, S., and Visscher, M. B., Changes in renal blood flow in relation to changes in pressure in urine formation. Proc. Soc. Exper. Biol. and Med., 1937, 36, 27.

8. Gremels, H., Uber die Wirkung einiger Diuretika am Starlingschen Herz-Lungen-Nierenpräparat. Arch. f. exper. Path. u. Pharmakol., 1928, 130, 61.

9. Grollman, A., Variations in the cardiac output of man. V. The cardiac output of man during the malaise and pyrexia following the injection of typhoid vaccine. J. Clin. Invest., 1929, 8, 25.

10. Hartmann, H., Ørskov, S. L., and Rein, H., Die Gefässreaktionen der Niere im Verlaufe allgemeiner Kreislauf-Regulationsvorgänge. Pflüg. Arch. f. d. ges. Physiol., 1937, 238, 239.

11. Hemingway, A., Some observations on the perfusion of the isolated kidney by a pump. J. Physiol., 1931, 71, 201.

12. Herrick, J., and Markowitz, J., The toxic effects of defibrinated blood when perfused through the isolated mammalian heart. Am. J. Physiol., 1929, 88, 698.

13. Hoen, E., and Neuthard, A., Pharmakologische Untersuchungen über das Minutenvolumen des normalen menschlichen Herzens. II. Der Einfluss von
Cardiazol, Coramin und Coffein.- Natr. salicyl. Arch. f. exper. Path. u. Pharmakol., 1937, 185, 302-308.

14. Janssen und Rein, Über die Zirkulation und Wärmebildung der Niere unter Einfluss von Giften. Arch. f. exper. Path. u. Pharmakol., 128, Verhandl. d. deutsch. Pharm. Gesellsch., 1928, 107.

15. Neuthard, A., and Hoen, E., Pharmakologische Untersuchungen über das Minutenvolumen des normalen menschlichen Herzens. I. Der Einfluss von Coffein, Theobromin, Theophyllin, Kaffee und Kaffee Hag. Arch. f. exper. Path. u. Pharmakol., 1937, 185, 293.

16. Opitz, E., and Smyth, D. H., Nierendurchblutung bei Reizung des Carotis-Sinus. Pflügers Arch. $f$. d. ges. Physiol., 1937, 238, 633.

17. Ozaki, M., Pharmakologie der Nierengefässe. Arch. f. exper. Path. u. Pharmakol., 1927, 123, 305.

18. Pitts, R. F., The excretion of phenol red by the chicken. J. Cell. and Comp. Physiol., 1938, 11, 99.

19. Ranson, S. W., Jr., Fever induced by the intravenous injection of typhoid-paratyphoid vaccine. Arch. Int. Med., 1938, 61, 285.

20. Rein, H., and Rössler, R., Die Abhängigkeit der vasomotorischen Blutdruckregulation bei akuten Blutverlusten von den thermoregulatorischen Blutverschiebungen im Gesamtkreislaufe. Ztschr. f. Biol., 1929, 89, 237.

21. Richards, A. N., and Plant, O. H., Urine formation in the perfused kidney. The influence of adrenalin on the volume of the perfused kidney. Am. J. Physiol., 1922, 59, 184.

22. Richards, A. N., and Plant, O. H., The action of minute doses of adrenalin and pituitrin on the kidney. Am. J. Physiol., 1922, 59, 191.

23. Rydin, H., and Verney, E. B., The inhibition of waterdiuresis by emotional stress and by muscular exercise. Quart. J. Exper. Physiol., 1938, 27, 343.

24. Shannon, J. A., The excretion of phenol red by the dog. Am. J. Physiol., 1935, 113, 602.

25. Smith, H. W., The Physiology of the Kidney. Oxford University Press, New York, 1937.

26. Smith, H. W., Goldring, W., and Chasis, H., The measurement of the tubular excretory mass, effective blood flow and filtration rate in the normal human kidney. J. Clin. Invest., 1938, 17, 263.

27. Smith, W. W., and Ranges, H., Renal clearances of iopax, neoiopax and skiodan in man. Am. J. Physiol., 1938, 123, 720.

28. Springorum, P. W., and Centenera, D., Die verschiedene Beteiligung beider Nieren an Diureseänderungen und vasomotorischen Reaktionen. Pflüg. Arch. f. d. ges. Physiol., 1937, 239, 440.

29. Starling, E. H., and Verney, E. B., The secretion of urine as studied on the isolated kidney. Proc. Roy. Soc., s. B, 1925, 97, 321.

30. Starr, I., Gamble, C. J., Margolies, A., Donal J. S., Jr., Joseph, N., and Eagle, E., A clinical study of 
the action of 10 commonly used drugs on cardiac output, work and size; on respiration, on metabolic rate and on the electrocardiogram. J. Clin. Invest., 1937, 16, 799.

31. Unna, K., Arterieller Druck und Nierendurchblutung. Pflüg. Arch. f. d. ges. Physiol., 1935, 235, 515.

32. Verney, E. B., and Winton, F. R., The action of caffeine on the isolated kidney of the dog. J. Physiol., 1930, 69, 153.

33. Walker, A. M., Schmidt., C. F., Elsom, K. A., and Johnston, C. G., Renal blood flow of unanesthetized rabbits and dogs in diuresis and antidiuresis. Am. J. Physiol., 1937, 118, 95.

34. Wilkins, R. W., Haynes, F. W., and Weiss, S., The rôle of the venous system in circulatory collapse induced by sodium nitrite. J. Clin. Invest., 1937, $16,85$.

35. Winton, F. R., The glomerular pressure in the isolated mammalian kidney. J. Physiol., 1931, 72, 361.

36. Winton, F. R., The control of the glomerular pressure by vascular changes within the isolated mammalian kidney, demonstrated by the actions of adrenaline. J. Physiol., 1931, 73, 151. 